\title{
A hybrid Kano-fuzzy AHP method for measuring customer satisfaction: A case study of transportation system
}

\author{
Mohammad Hemati $^{\mathrm{a}^{*}}$ and Fozieh Ghorbanian ${ }^{\mathrm{a}}$
}

${ }^{a}$ Department of Business Management,Islamic Azad University, Semnan Branch, Iran

\begin{tabular}{|c|c|}
\hline A R T I C L E I N F O & A B S T R A T T \\
\hline $\begin{array}{l}\text { Article history: } \\
\text { Received January } 152011 \\
\text { Accepted } 8 \text { April } 2011 \\
\text { Available online } \\
10 \text { April } 2011 \\
\text { Keywords: } \\
\text { Services quality } \\
\text { Customers satisfactory } \\
\text { Kano Model } \\
\text { Fuzzy analytical hierarchy process }\end{array}$ & $\begin{array}{l}\text { An increase competition on today's economy has created motivation for many organizations to } \\
\text { look for different alternatives on better serving the customers. There are always some budget } \\
\text { limitations on any customer relationship method, which leads us to prioritize different } \\
\text { alternatives. In this paper, we present an empirical method based on an integrated Kano and } \\
\text { fuzzy analytical hierarchy procedure to rank suitable alternatives. The proposed model of this } \\
\text { paper uses a questionnaire survey to gather customer's opinions and implements the method for } \\
\text { a real-world case study of transportation planning. The questionnaire includes } 37 \text { questions } \\
\text { distributed among } 976 \text { passengers for two trips in Iran. The results indicate that driver's } \\
\text { physical and mental health, buss equipments with GPS functionality and familiarity of drivers } \\
\text { with road and road's conditions play important role on choosing a transportation company. }\end{array}$ \\
\hline
\end{tabular}

C 2011 Growing Science Ltd. All rights reserved.

\section{Introduction}

During the past few decades, there have been enormous number of works focused on service quality models (Teas, 1994; Ghobadian et al., 1994; Wassenaar, 2005; Xu, 2009). Grönroos (1984) presented a service quality model and its marketing implications based on examining a sample of business executives, which describes how customers perceive the quality of services. He explained that functional quality is a very important dimension of a perceived service and concluded that quality dimensions are interrelated. Lee et al. (2011) performed a study to examine the effects of consumers' service quality perceptions on satisfaction, revisit intention and the role of gender for high profile golf club business. They investigated the role of gender in forecasting their service quality perceptions and the relationship between quality perceptions and satisfaction and intention.

$\mathrm{Xu}$ et al. (2008) studied the inherent issues of traditional Kano method by proposing an analytical Kano technique based on focusing on customer need analysis. The Kano principles were originally proposed to incorporate quantitative measures into customer satisfaction where two methods were developed to provide decision support for product design. The first Kano classifiers are normally used as tangible criteria for categorizing customer needs, and the second configuration index is for product configuration design. They used A-Kano for a case study of dashboard in automotive design and

* Corresponding author. Tel. ++98-231-4458230

E-mail addresses: mo928hem@yahoo.com (M. Hemati) 
demonstrated that the model can incorporate customer preferences in product design by a tradeoff between customer's satisfaction and producer's capacity. K rn et al. (2009) showed that customer satisfaction in construction is relatively complicated issue in which different factors have different impacts on the quality as perceived by the customer. Management and factors associated with skills have also different impacts on the factors describing the end result and methods of the project. Based on the results of $\mathrm{K}$ rn et al., the contractor's ability to cooperate is divided into two directions of managing changes and communication. The results of their studies also emphasize the importance of communication in project production where it is recommended thatthe contractors must focus on developing and improving their central processes to increase the level of their services. Ha and Jang (2010) studied the impact of service quality and food quality using a comprehensive framework.

Li et al. (2008) presented an integrated method of rough set, Kano's model and analytical hierarchy procedure (AHP) for ranking customer requirements' final importance. Their proposed model ranks customer requirements in product planning house of quality. Chen (2008) investigated structural relationships between service quality, perceived value, satisfaction, and behavioral intentions for air passengers for a case study of a real-world in Taiwan. Caruana (2002) studied service loyalty using the effects of service quality and customer satisfaction. Dabholkar et al. (2000) presented a comprehensive framework for service quality using an integrated model. Lee et al. (2010) developed an econometrics analysis of the R\&D performance in the national hydrogen energy technology development for measuring relative efficiency using an integrated fuzzy AHP (saaty, 1992) and data envelopment analysis.

Analyzing customers need is one of the most important duties of produces and interpret that the customers beliefs and market situations can increase the success of businesses (Parassuraman et al., 1988). Since customer plays a vital role on the success of different businesses there are different methods to understand customers' needs. One of the most important methods called Kano is a qualitative instrument which is registered about customers compete analysis and help to understand voice of customers and their effectiveness on customers satisfactory (Jamal \& Naser, 2002). According to this concept, Kano model analyzes the customer's needs and study different parameters affecting customer's needs (Ting \& Ping, 2009; Wang \& Ji, 2010). However, this model does not have quantitative instruments and does not reflect differences among a group's needs. Li et al. (2009) presented an integrated method of rough set, Kano's model and AHP for rating customer requirements' final importance. Rivière et al. (2006) presented an adaptive preference target to measure the contribution of Kano's model of satisfaction for an optimized preference analysis using a sequential consumer test.

The present study of this paper uses an integrated Kano and AHP method to rank the most important issues that customers consider when they are travelling via busses between different cities. This paper is organized as follows. We first present the methodology of the proposed model in section 2. Section 3 demonstrates the implementation of the proposed model analyzes the results. Finally concluding remarks are given in section 4 to summarizes the contribution of the paper.

\section{Theoretical framework}

\subsection{Quality of services}

According to the vast researches, one of the most important factors that affects on customers satisfactory and their structure behaviors about services marketing, is quality of services. Quality of services on different areas could have different meaning. Quality of services includes understanding the customer from relative goodness of an institution or service provider. Quality can be defined also as customers justice of total preference or relative preference of services (Zeithaml, 1988). Services include total characteristics of customer mentioned on institution (Kassim, 2010). Quality is the results of something that customer receive really and quality of process explains how the services imposed (Grönroos, 1984; 1990). There are four characteristics associated with service quality which are: un-touch, ability to disappear, un-homogeneity and synchronous. Those functions, which are 
experienced by customers, are called un-touch ability. Disappearing emphasizes on the services, which would not be produced or reserved for future. Un- homogeneity reflects the services, which are different from one to another. The last one is synchronicity that refers to the services produced in present time and should be consumed. Therefore, a customer cannot judge about productions quality before consuming the service ( Berry \& oarasuraman, 1991).

\subsection{Customers satisfactory}

Customers satisfactory is one of the important theoretical and empirical objects for most marketfinders and marketing researchers, that is mentioned as a necessary and important condition to compete on newly universal market ( Jamal \& Naser. 2002). Therefore, their satisfactory importance and customers' maintenance on strategy collection for customer-having companies are important issues. Therefore, the most accepted theory to explain customers' satisfaction is an unconfirmed theory, which sates satisfaction degrees by comparing the experiences or real function against their expectations. Universal satisfaction or un-satisfaction is called total satisfaction. Satisfactory repletion itself is a question with collection satisfaction, which is an indicator of past, present, and future of company.

\subsection{Quality of services and customers satisfaction}

Customer satisfaction is a total concept, which shows total result of reaction consumption and includes area of unsatisfactory toward satisfaction.

\section{Research methodology}

\subsection{Kano model}

Kano model is an economical method to access clients satisfaction on compete analysis and deep understanding about voice of customer. Kano model is used to grade products' characteristics according to customers' needs. In fact, Kano graph shows customers' satisfactory associated with production level and survey the quality of products. According to Kano, to provide customers' satisfaction, institutions must remove any obligations, which affect the customers. Satisfactory and products and services should provide all three kinds of needs.

\subsubsection{Expectation (Fundamental) obligations}

According to Kano's model, the fulfillment of the fundamental needs only prevents customers' unsatisfactory and does not have any influence on customers' unsatisfactory.

\subsubsection{Functional obligations}

The second group of quality characteristics is associated with functional needs about products. If functional needs are not met, customers may not be satisfied. It is always important to recognize this kind of needs which is the minimum effort which could be done.

\subsubsection{Exciting obligations}

It is normally difficult to discover and determine the obligations since these are not easy achieve.

\subsubsection{The Kano structure}

There is asimple and comprehensive method to present Kano's model which is shown in Table 1. As we can observe from Table 1, there are some questions associated with Kano's model to be analyzed.

\section{Table 1}

Assessment the results of customers needs

\begin{tabular}{|c|c|c|c|c|c|c|}
\hline \multirow{6}{*}{ 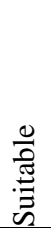 } & Customers needs & very positive effect & positive effect & without effect & negative effect & very negative effect \\
\hline & very positive effect & $\mathrm{Q}$ & A & A & A & $\mathrm{Q}$ \\
\hline & positive effect & $\mathrm{R}$ & I & I & I & M \\
\hline & without effect & $\mathrm{R}$ & I & I & I & M \\
\hline & negative effect & $\mathrm{R}$ & I & I & I & M \\
\hline & very negative effect & $\mathrm{R}$ & $\mathrm{R}$ & $\mathrm{R}$ & $\mathrm{R}$ & $\mathrm{Q}$ \\
\hline
\end{tabular}




\subsection{Fuzzy AHP}

There are many cases where we have more than one qualitative criterion for decision-making. In such a case, we may use multiple criteria decision making (MCDM) methods such as AHP to reach a fair final decision. There are literally different versions of AHP methods and the one we use is based on fuzzy concept. In AHP, we perform pairwise comparison among different criteria and in fuzzy AHP we use linguistic verbs to perform the comparison. Although, Fuzzy AHP (FAHP) needs heavy computational process, but it is more systematic than other MCDM methods. FAHP handles paired compare of indicators and standards, vague and clearness of human's assessments. An ordinary AHP normally gathers pairwise comparison for different alternatives based on various criteria and based on two-stage normalization processes determines the ranking of the alternatives with respect to each criterion. Similar procedure is also repeated for all criteria in the second step and the overall ranking of different alternatives found in the first step is established based on the weights found from the second step. Lee et al. (2010) used triangular fuzzy numbers in forms of the linguistic numbers for ranking procedure. The details of the computations can be found in Lee et al. (2010) and is not repeated in this paper. Table 2 summarizes the triangular fuzzy numbers used for the proposed model of this paper (Lee et al., 2010).

\section{Table 2}

Triangular fuzzy numbers

\begin{tabular}{lcllcc}
\hline Linguistics variables & The same & Low & High & Very high & Completely higher \\
\hline Triangular fuzzy number & $(1,1,1)$ & $(2.3,1,3.2)$ & $(3.2,2,5.2)$ & $(5.2,3,7.2)$ & $(7.2,4,9.2)$ \\
\hline
\end{tabular}

\subsection{Method of research}

There are different stages for the proposed model of this paper. In the first stage, we interviewed some experts to find the most important issues affecting customer satisfaction. In this stage, we also interviewed passengers who filed complaint with different transportation organizations as a necessary feedback for preparing the necessary questions. The final questionnaire has included 37 questions about passenger's needs quality of services on road transportation. The questions of this questionnaire have been divided into three groups of necessary, attractive and functional using the Kano table. Next, we have used FAHP to prioritize different alternatives. The proposed model of this paper was applied for two paths located in east and north parts of the country. The first trip was between Tehran to Mashad and the second trip was from Tehran to Rasht. We distributed 377 questionnaire for the first trip and 599 questionnaire for the second trip. We have used the following sampling procedure to find out where the number of questionnaire is sufficient or not.

$$
n=\frac{N \times z_{\alpha / 2}^{2} \times p \times q}{\varepsilon^{2} \times(N-1)+z_{\alpha / 2}^{2} \times p \times q},
$$

where $N$ is the population size, $p=1-q$ represents the yes/no categories, $z_{\alpha / 2}$ is CDF of normal distribution and finally $\varepsilon$ is the error term. Since we have $p=0.5, z_{\alpha / 2}=1.96$ and $\varepsilon=0.004$. The results confirm that the number of questionnaire is sufficient for our survey.

Table 3

Personal characteristics of the people participating in the survey

\begin{tabular}{|c|c|c|c|c|c|}
\hline \multirow[b]{2}{*}{ Age(Years) } & $<20$ & $20-30$ & $31-40$ & $41-50$ & $>50$ \\
\hline & 86 & 415 & 261 & 162 & 24 \\
\hline \multirow{3}{*}{$\begin{array}{l}\text { Educational } \\
\text { background(Years) }\end{array}$} & $<12$ & 14 & 16 & 18 & \\
\hline & 125 & 117 & 568 & 96 & \\
\hline & Pilgrim & Tour & Work & Study & \\
\hline \multirow{3}{*}{$\begin{array}{l}\text { Travel purpose } \\
\text { Occupation }\end{array}$} & 293 & 175 & 44 & 412 & \\
\hline & Public sector & Private sector & University student & House keeper & Others \\
\hline & 198 & 161 & 397 & 91 & 77 \\
\hline
\end{tabular}


In order to use the filled questionnaire we carefully check to see whether all questions have been responded, properly and eliminated the incomplete ones. Out of 926 questionnaire used for statistical analysis there were 513 men and 411 women. Table 3 demonstrates other characteristics of the people who participate in our survey. As we explained earlier, there three criteria of attractive, onedimensional and obligation needs. We gathered various factors for each criteria and using a FAHP ranked these factors. Table 4 summarizes the results of the implementation of FAHP for three major criteria.

\section{Table 4}

FAHP results for major criteria

\begin{tabular}{lllll}
\hline & Obligation needs & One - dimensional & attractive & $\mathrm{W}_{\text {FAHP }}$ \\
\hline Obligation needs & $(1,1,1)$ & $(1.3,1.6,2)$ & $(2.7,3.2,3.7)$ & 0.543 \\
One - dimensional & $(0.62,0.77,1.02)$ & $(1,1,1)$ & $(2.1,2.6,3.1)$ & 0.321 \\
attractive & $(0.3,0.33,0.42)$ & $(0.34,0.4,0.52)$ & $(1,1,1)$ & 0.136 \\
\hline
\end{tabular}

The consistency ratio for the information given in Table 4 is about 0.04 , which confirms the results of our survey at this level. There are different factors for each criteria compared with FAHP method. Tables 5 to 7 summarize the results of our survey.

Table 6

The implementation of FAHP for obligation criterion

\begin{tabular}{llc}
\hline Rank & Index & W $_{\text {FAHP }}$ \\
\hline 1 & Physical and mental health of driver and driver-mate & 0.16 \\
2 & Comfortable chairs in transportation busses & 0.16 \\
3 & A good guidance from driver & 0.143 \\
4 & Well equipped air-conditioned facilities & 0.114 \\
5 & Best maintenance of instrument and things & 0.101 \\
6 & Equipped with Immune facilities & 0.092 \\
7 & Clean buss environment & 0.087 \\
8 & Good information about the available space of movement & 0.05 \\
9 & Having Hygienic places and clear lines of service places between ways & 0.039 \\
10 & Cleanliness of hygiene services on passenger service terminal & 0.023 \\
11 & Cleanliness of terminal place for passengers & 0.023 \\
\hline 12 & Well equipped air-conditioned facilities inside the terminal busses & 0.008 \\
\hline
\end{tabular}

The consistency ration of the implementation of FAHP for obligation criterion is calculated to be 0.066, which is an acceptable number. As we can observe from Table 6, physical and mental health of driver and driver-mate along with comfortable chairs play the most important role on this criterion.

Table 7

The implementation of FAHP for one dimension criterion

\begin{tabular}{lll}
\hline Rank & \multicolumn{1}{c}{ One-dimension criterion } & WAHP $_{\text {FAn }}$ \\
\hline 1 & The availability of GPS and other high tech facilities & 0.16 \\
2 & Punctuality and on time schedule & 0.129 \\
3 & Existence of cold and hot water in the bus & 0.117 \\
4 & Behavior of ticket sellers and terminal workers & 0.086 \\
5 & Suitable behavior of driver-mat & 0.073 \\
6 & The availability of reception for passengers inside the buses \\
7 & Giving newspaper and magazine inside the bus & 0.067 \\
8 & Welfare facilities inside the terminal (Hand wheeled, public telephone, etc) \\
10 & Well-dressed driver and driver-mate with good uniform and clean clothes \\
12 & Collecting intermediates for sale ticket & 0.065 \\
13 & The availability of show case movies inside the buses & 0.059 \\
\hline
\end{tabular}

The consistency ratio for the results of Table 7 is .09, which is on the acceptance level and the main feature, which is considered as the most important issue is the equipments of the buss such as GPS facilities. Finally, Table 8 shows the details of the FAHP implementation for attractive needs. 


\section{Table 8}

The implementation of FAHP for attractive needs criterion

\begin{tabular}{llc}
\hline Rank & \multicolumn{1}{c}{ One-dimension criterion } & W $_{\text {FAHP }}$ \\
\hline 1 & Basic knowledge with first aid assistance and medical care & 0.14 \\
2 & The availability of internet or phone service to purchase ticket & 0.12 \\
3 & Using Headphone to hearing film and music sound & 0.11 \\
4 & Increase the number of services and welfare building between ways & 0.098 \\
5 & The availability of a bus to physician, nurse or medical cares & 0.097 \\
6 & The availability of a place for injured people & 0.09 \\
7 & Having a hostess in bus & 0.084 \\
8 & The availability of a SMS service to make complaints on the bus services & 0.08 \\
9 & Good quality of sitting chairs inside the terminals & 0.073 \\
10 & The possibility of increasing capacity of Tehran trip & 0.049 \\
11 & The availability of special services on terminal and inside the terminal & 0.034 \\
12 & Equipped buses with communicational facilities (card phone, fax, etc ...) & 0.025 \\
\hline
\end{tabular}

Note that the consistency ratio for the implementation of FAHP is calculated as 0.09 , which indicates that the results are acceptable. As we can observe from the table customers prefer to go to trip with those drivers with some basic knowledge of first aid assistance. The relative importance of each criterion given in Table 6, 7 and 8 are combined using the relative importance of each major criterion given in Table 5 and they are summarized in Table 9.

\section{Table 9}

The overall priorities for sub- indicators of road transportation services among special buses based on (FAHP)

\begin{tabular}{|c|c|c|}
\hline Rank & Title & $\mathrm{W}_{\mathrm{FAHP}}$ \\
\hline 1 & Physical and mental health of driver and driver-mate & 0.087 \\
\hline 2 & A good guidance from driver & 0.078 \\
\hline 3 & Comfortable chairs in transportation busses & 0.087 \\
\hline 4 & Well equipped air-conditioned facilities & 0.062 \\
\hline 5 & Equipped with Immune facilities & 0.05 \\
\hline 6 & Best maintenance of instrument and things & 0.051 \\
\hline 7 & Clean buss environment & 0.047 \\
\hline 8 & The availability of GPS and other high tech facilities & 0.055 \\
\hline 9 & Punctuality on time schedule & 0.042 \\
\hline 10 & Existence of cold and hot water in the bus & 0.038 \\
\hline 11 & Good information about the available space of movement & 0.027 \\
\hline 12 & Behavior of ticket sellers and terminal workers. & 0.028 \\
\hline 13 & Having Hygienic places and clear lines of service places between ways & 0.021 \\
\hline 14 & The availability of reception for passengers inside the buses & 0.022 \\
\hline 15 & Giving newspaper and magazine inside the bus & 0.021 \\
\hline 16 & Suitable behavior of driver-mat & 0.023 \\
\hline 17 & Well-dressed driver and driver-mate with good uniform and clean clothes & 0.019 \\
\hline 18 & Cleanliness of terminal place for passengers & 0.0125 \\
\hline 19 & Welfare facilities inside the terminal ( Hand wheeled public telephone and ... ) & 0.019 \\
\hline 20 & Cleanliness of hygiene services on passenger service terminal & 0.0125 \\
\hline 21 & exclusion intermediates for sale ticket & 0.018 \\
\hline 22 & Familiarity with assistance periods and first aids among drivers and drivers-mat & 0.019 \\
\hline 23 & The availability of show case movies inside the busses & 0.014 \\
\hline 24 & Fixed price for bus ticket & 0.014 \\
\hline 25 & Good quality of food services & 0.013 \\
\hline 26 & The availability of internet or phone service to purchase ticket & 0.016 \\
\hline 27 & Increase the number of services and welfare building between ways & 0.013 \\
\hline 28 & The availability of a bus to physician, nurse or medical cares & 0.013 \\
\hline 29 & Using Headphone to hearing film and music sound & 0.015 \\
\hline 30 & Collecting intermediates for sale ticket & 0.004 \\
\hline 31 & The availability of a place for injured people & 0.012 \\
\hline 32 & The availability of a SMS service to make complaints on the bus services & 0.011 \\
\hline 33 & Having a hostess in bus & 0.011 \\
\hline 34 & Good quality of sitting chairs inside the terminals & 0.01 \\
\hline 35 & The possibility of increasing capacity of Tehran trip & 0.007 \\
\hline 36 & The possibility of increasing capacity of Tehran trip & 0.005 \\
\hline \multirow[t]{2}{*}{37} & Equipped buses with communicational facilities ( card phone, fax and ...) & 0.003 \\
\hline & Total & 1 \\
\hline
\end{tabular}


As we can observe from Table 9, six factors play important roles on customer satisfaction. The first and the most important factor is physical and mental health of driver and driver-mate followed by a good guidance from driver and comfortable chairs in transportation busses. In addition, the availability of a well equipped air-conditioned facilities and the immune facilities as well as good maintenance of the equipment and clean buss facilities are important factors for customer satisfaction. The customers tend to believe that drivers could use high technology facilities such as GPS to reach their destinations.

There are some evidences that many bus or truck drivers used to be addicted to drugs. On the other hand, there are many incidents in Iran that bus driver faced with fatal accidents solely because the bus driver was suffering from drug usage side effects. Therefore, the customers who participated in our survey were very much concerned on having a trip with drivers with good health condition and no history of drug usage. The people who took part in our survey were willing to have a comfortable trip and a good sitting chair with good air-condition facilities could help, significantly having a pleasant trip.

The other important factor in recent bus accidents is violating transportation laws and feeling sleepy. Although the results of this survey do not explicitly show this fact but there are many statistics to confirm that government's officials must provide restaurants and other places such that drivers would be able to rest.

\section{Conclusion}

In this paper, we have presented an empirical survey to study the most important issues affecting customer satisfaction. The proposed model of this paper used a combination of Kano method and fuzzy analytical hierarchy process. In our survey, Kano method was used to find the most important criteria for customer satisfaction and fuzzy AHP was implemented to rank the criteria. The results of our survey indicated that customers were very much concerned for drivers with good health conditions. The customers who participated in our survey preferred to use the buses with good quality facilities such as flexible sitting chair, air-conditioned equipments, etc.

\section{Acknowledgment}

This research was financially supported by ministry of transportation and we would like to gratefully thank the people who share their insight.

\section{References}

Berry, L. L., \& Parasuraman, A. (1991). Marketing services: Competing through quality. New York, NY: The Free Press.

Chen, C. F. (2008). Investigating structural relationships between service quality, perceived value, satisfaction, and behavioral intentions for air passengers: evidence from Taiwan. Transportation Research Part A, 42, 709-717.

Caruana, A. (2002). Service loyalty: The effects of service quality and the mediating role of customer satisfaction. European Journal of Marketing, 36(7/8), 811-830.

Chen, C. C., \& Chuang, M. C. (2008). Integrating the Kano model into a robust design approach to enhance customer satisfaction with product design. International Journal of Production Economics, 114(2), 667-681.

Dabholkar, P. A. Shepherd, C. D., \& Thorpe, D.I (2000). A comprehensive framework for service quality: an investigation of critical conceptual and measurement issues through a longitudinal study. Journal of Retailing, 76(2), 139-173.

Ghobadian, A., Speller, S., \& Jones, M. (1994). Service quality: Concepts and models. International Journal of Quality and Reliability Management, 11, 43-66.

Grönroos, C. (1984). A service quality model and its marketing implications. European Journal of Marketing, 18(4), 36-45.

Grönroos, C. (1990). Service Management and Marketing. Lexington Books, Toronto. 
Ha, J. \& Jang, S. (2010). Effects of service quality and food quality: The moderating role of atmospherics in an ethnic restaurant segment. International Journal of Hospitality Management, 29(3), 520-529.

Jamal, A. \& Naser, K. (2002). Customer Satisfaction and retail banking: an assessment of some of the key antecedent of customer satisfaction in retail banking. International Journal of Bank Marketing, 20,146160.

Kassim, N. (2010). The effect of perceived service quality dimensions on customer satisfaction, trust, and loyalty in e-commerce settings. A Cross Cultural Analysis, 22(3), 351-371.

K rn , S., Junnonen, J. M., \& Sorvala, V. M. (2009). Modelling structure of customer satisfaction with construction. Journal of Facilities Management, 7(2), 111-127.

Lee, J. H., Kim, H. D., Ko, Y. J., \& Sagas, M. (2011). The influence of service quality on satisfaction and intention: A gender segmentation strategy. Sport Management Review, 14(1), 54-63.

Lewin, K., (1938). The conceptual representation and measurement of psychological forces. University Press, Durham, NC.

Lee, S. K., Mogi, G., Kim, J. W. (2009). Decision support for prioritizing energy technologies against high oil prices: a fuzzy analytic hierarchy process approach. Journal of Loss Prevention in the Process Industries, 22. 915-920.

Lee, S. K., Yoon, Y. J., Kim, J. W. (2007). A study on making a long-term improvement in the national energy efficiency and GHG control plans by the AHP approach. Energy Policy, 35, 2862-2868.

Lee, S. K., Mogi, G., Lee, S. K., Hui, K. S. \& Kim, J. W. (2010). Econometric analysis of the R\&D performance in the national hydrogen energy technology development for measuring relative efficiency: The fuzzy AHP/DEA integrated model approach. International Journal of Hydrogen Energy, 35(6), 2236-2246.

Li, Y., Tang, J., Luo, X., \& Xu, J.(2009). An integrated method of rough set, Kano's model and AHP for rating customer requirements' final importance. Expert Systems with Applications, 36(3),7045-7053.

McKay, A., de Pennington, A. \& Baxter, J. (2001). A representation scheme for product. Computer Aided Design, 33, 511-520.

McDougall, G. H. G., \& Levesque, T. (2000). Customer satisfaction with services: Putting perceived value into the equation. Journal of Services Marketing, 14(5), 392-410.

Parassuraman. A, Valarie A. Z., Leonard L. B. (1988). SERVQUAL:A multiple-item scale for measuring consumer perceptions of service quality. Journal of Retailing, 64(1), 12-40.

Rivière, P., Monrozier, R., Rogeaux, M., Pagès, J. \& Saporta, G. (2006). Adaptive preference target: contribution of Kano's model of satisfaction for an optimized preference analysis using a sequential consumer test. Food Quality and Preference, 17, 572-581.

Saaty, T. L. (1992). How to make a decision: the analytic hierarchy process. European Journal of Operational Research, 48, 9-26.

Teas, R. K. (1994). Expectations as a comparison standard in measuring service quality: An assessment of a reassessment. Journal of Marketing, 58, 132-139.

Wang, T. \& Ji, P. (2010). Understanding customer needs through quantitative analysis of Kano's model. International Journal of Quality \& Reliability Management, 27(2), 173-184.

Wassenaar, H. J., Chen, W., Cheng, J., \& Sudjianto, A. (2005). Enhancing discrete choice demand modeling for decision-based design. ASME Journal of Mechanical Design, 127, 514-523.

Xu, Q., Jiao, R. J.,Yang, X., Helandera, M., Khalid, H. M., \& Opperud, A.(2009). An analytical Kano model for customer need analysis. Design Studies, 30(1), 87-110.

Zeithaml, V. A. (1988). Consumer perceptions of price, quality and value: a means-end model and synthesis of evidence. Journal of Marketing, 52, 2-22. 